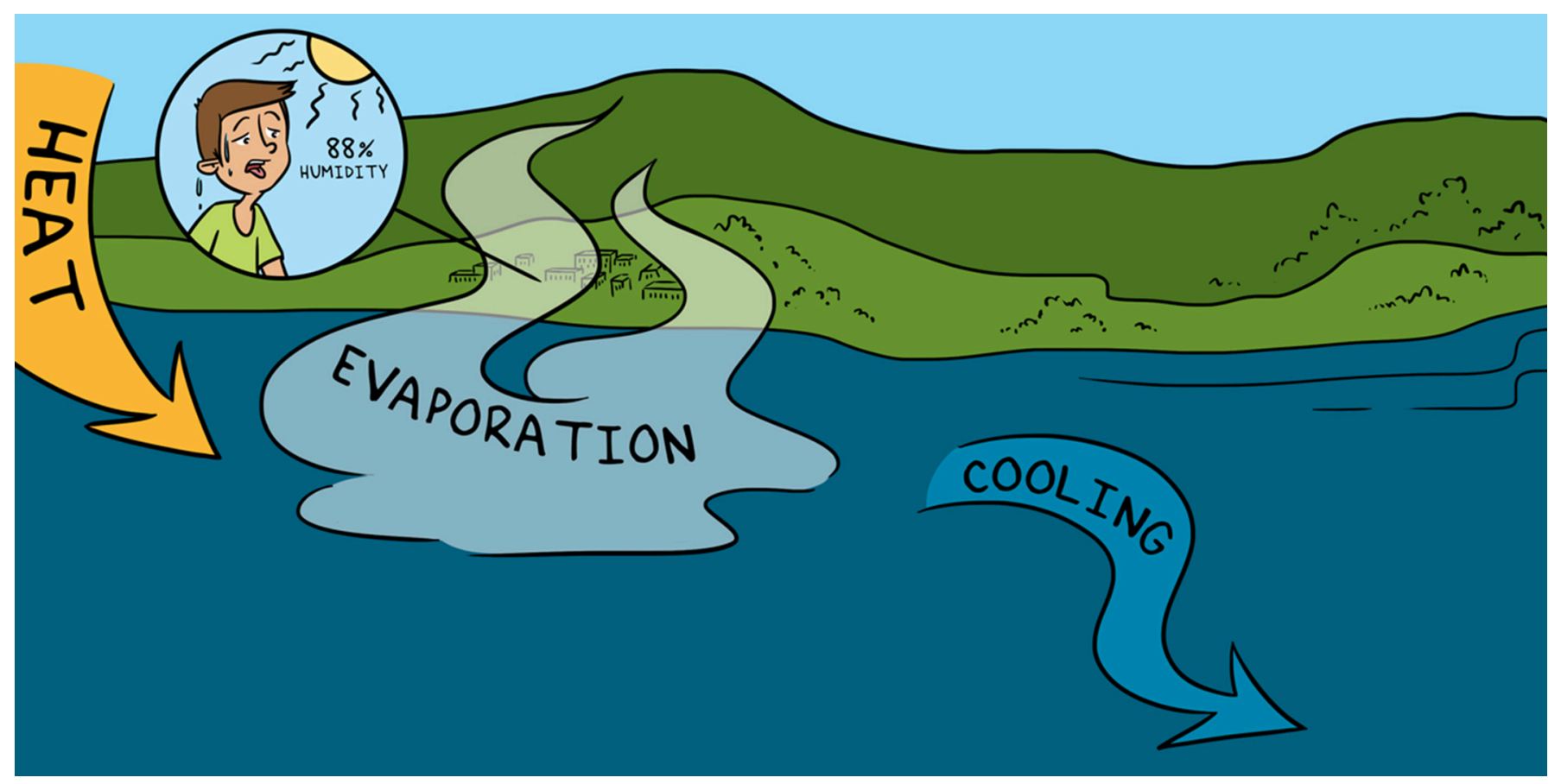

\title{
HOW MIGHT THE OCEAN CHANGE IN THE FUTURE?
}

\section{Denise Tyemi Fukai ${ }^{1 *}$, Anna Beatriz Jones Oaquim ${ }^{2}$ and Mauro Cirano ${ }^{1,3}$}

${ }^{1}$ Physical Oceanography Laboratory, Postgraduate Program in Meteorology, Institute of Geosciences, Federal University of Rio de Janeiro, Rio de Janeiro, Brazil

${ }^{2}$ Global Changes and Radioecology Laboratory, Department of Biophysics and Biometrics, Institute of Biology Roberto Alcantara Gomes, Rio de Janeiro State University, Rio de Janeiro, Brazil

${ }^{3}$ Physical Oceanography Laboratory, Department of Meteorology, Institute of Geosciences, Federal University of Rio de Janeiro, Rio de Janeiro, Brazil

YOUNG REVIEWER:

AVIV

AGE: 9
The ocean is one of the main components of the climate system. It distributes and absorbs heat to regulate climate at different time scales. Temperature and salinity (saltiness) control the density of ocean water. Differences in water density are important for ocean circulation-they are responsible for generating some currents of water that move through the ocean. An important part of ocean circulation is called thermohaline circulation. Thermohaline circulation absorbs, stores, and transfers heat around the world. Changes in the temperature or salinity of ocean waters can affect thermohaline circulation, so climate change may also alter this circulation. Changes in water circulation also impact the ocean's chemistry and the organisms that live in the ocean. First, we will explain how ocean circulation happens, and then we will look at how climate change can affect it. 
OCEANIC

CIRCULATION

Large scale movement of waters made by ocean currents.

\section{DENSITY}

The ratio between the mass and volume of an object.

\section{SALINITY}

The amount of salt dissolved in a water body.

\section{OCEAN}

\section{STRATIFICATION}

The division of ocean water into layers based on density.

\section{WATER MASSES}

Water parcels with formed at the same place that travels around with similar characteristics for properties like temperature and salinity.

\section{HOW DOES THE OCEAN WORK?}

The ocean covers about $70 \%$ of the planet's surface and contains $97 \%$ of Earth's water. This water absorbs heat from the sun and transports this heat with the ocean currents. In addition to heat, ocean currents also transport carbon dioxide, nutrients, and organisms such as fish larvae all around the globe.

This transport is called oceanic circulation, and it has two major components. The first is the upper-ocean circulation, which is wind-driven and faster. It tends to happen only within a given ocean basin (the North Atlantic Ocean or the Indian Ocean basin, for example). Upper-ocean circulation helps to exchange heat and moisture between the ocean and the atmosphere. Therefore, changes in upper-ocean circulation can impact global and regional weather. The second component is the deep global circulation, which is slower and driven by differences in water density. It is the central part of the "global ocean conveyor belt". For more information see this Young Minds article: When Water Swims in Water, Will it Float, or Will it Sink? Or: What Drives Currents in the Ocean? [1]. Furthermore, the deep global circulation distributes heat and energy around the Earth across different ocean basins. Changes in the deep global circulation act over long timescales and can affect the local and global climate, as we have seen over the last 50,000 years. It is good to note that the difference between "weather" and "climate" is the time scale. When we talk about "weather" we refer to processes in the short time scale and climate, to the mean state of nature when averaging longer periods. For example, if it starts to rain in the desert, we can say that we are experiencing rainy weather. But for years, we have seen that it generally does not rain much in this region, so the desert has a dry climate despite the current rainy weather.

How does the difference in water density drive the deep global circulation? The density of ocean water varies with salinity (saltiness) and temperature, so water density varies throughout the ocean. Different regions and depths will have different salinity and temperature, and thus different densities. The warmer liquid water is, the lighter and less dense it gets. But solid ice is actually less dense than liquid water due to the structure of the ice crystals. This is why ice floats on water, even though it has a lower temperature than the liquid water it floats in. Thus, areas of cold and salty water are denser than areas of warm and fresh water. In the ocean, denser water parcels flow beneath lighter ones. Water parcels in the ocean are layered according to their density, much like a birthday cake with several layers and fillings. This forms the ocean stratification illustrated in Figure 1.

Temperature and salinity ranges define a water parcel. These parcels are what we call water masses. By studying water masses, we can understand where they came from and where they are going, which helps us better understand and describe the ocean. Water masses 
Figure 1

Ocean stratification is the separation of water into layers based on its density. Salinity (the amount of salt) and the temperature of the water contribute to density. When more rain falls or when glaciers melt, and when the sun heats the ocean water, the density of the water decreases (left panel). When water density decreases, this can create stable layers of water (right panel). Under these conditions, it is more difficult for water masses to form.

\section{THERMOHALINE} CIRCULATION

Part of the large-scale ocean circulation driven by density gradients. Results from the combined effects of temperature (thermo) and salt (haline) on density. Also called the ocean conveyor belt.

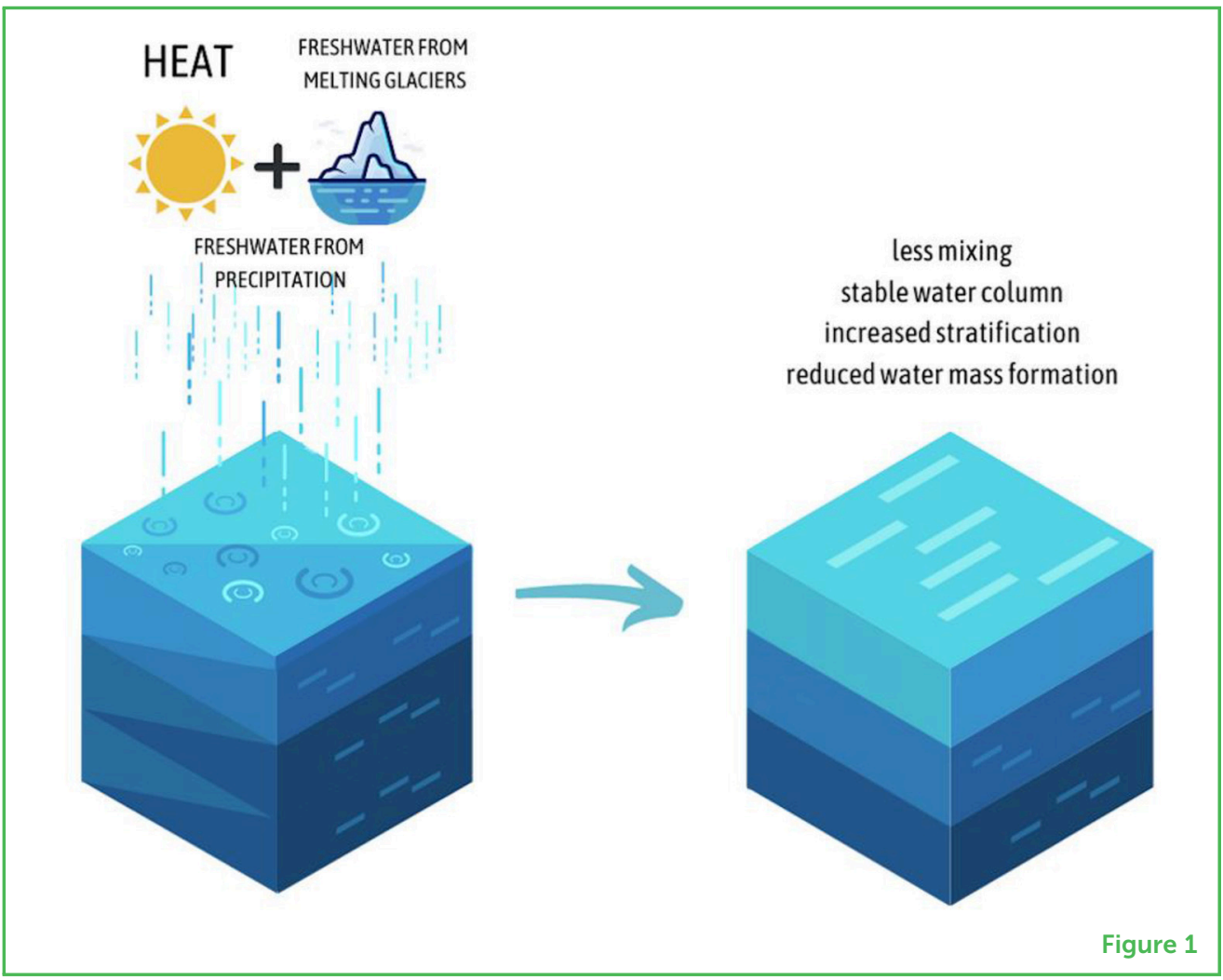

need the right combination of conditions to form. These conditions may include winds, solar radiation, and salt availability, which may only occur during specific seasons and in specific regions around the globe-in the North Atlantic or the Southern Ocean, for example.

\section{OCEAN AND CLIMATE: HEAT TRANSPORT}

The formation of deep-water masses is the fuel for what is called thermohaline circulation. The Atlantic Meridional Overturning Circulation (AMOC) is an important part of the thermohaline circulation. It is a north-south-oriented flow of water that transports heat in the Atlantic Ocean. Starting at the surface, the AMOC is composed of salty, warm waters from the low latitudes (near the Equator). Then, it flows toward the North Atlantic Ocean, where the ocean current called the Gulf Stream plays a key role. As the AMOC flows north, it slowly loses heat to the atmosphere because of the large difference in temperature between the air and the ocean. After losing heat, the water becomes denser and sinks, flowing back southwards (Figure 2).

At the same time, the warm, moist air above the AMOC current is taken by the winds. A similar thing happens when you forget about your cup of tea-it slowly starts to get cooler until it reaches room temperature. To achieve equilibrium, the hot tea must lose heat and moisture to the air just above your mug. But this warm, moist air does not stay 


\section{Figure 2}

Heat circulation in the North Atlantic. The ocean absorbs heat from the sun near the Equator and transports it northwards. As it is transported, the water evaporates and cools down. Evaporation causes heat and moisture to be transferred from the water to the air above. The atmospheric circulation redistributes all this heat and moisture. As the current goes further north, it becomes much colder and saltier. Finally, it is mixed and creates a new water mass with a higher density that sinks to deeper layers and flows back to the south (Image credit: Thiago Sales)

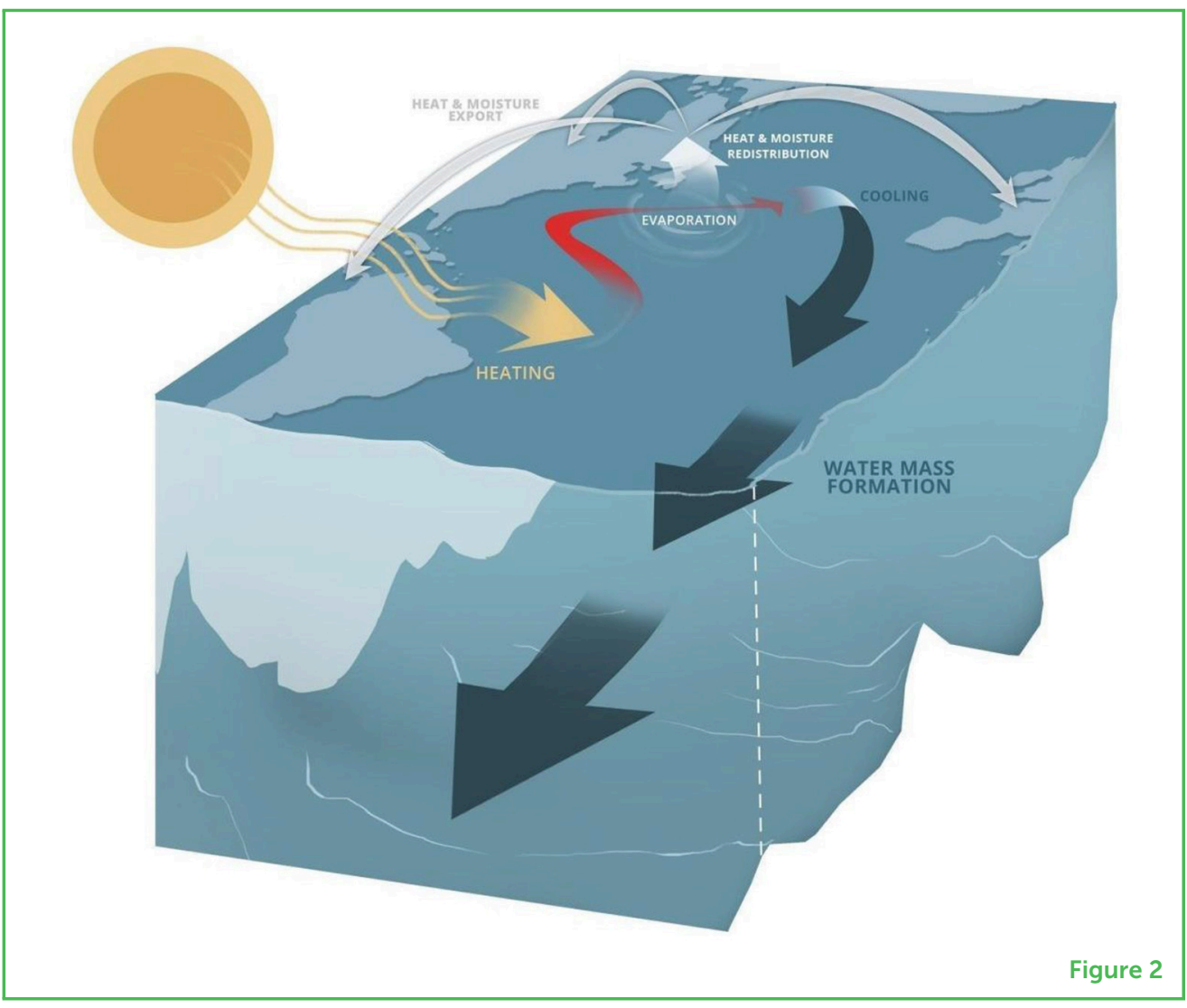

concentrated around the cup forever. Instead, it is dispersed in the room until you cannot track it anymore. The warm, moist air from the AMOC is taken by the winds and travels very far, reaching cities as far away as London. This makes the weather in London warmer and more humid compared to other cities found at the same latitude.

Now you can see why the AMOC is an essential component of the Earth's climate system-because it plays a crucial role in heat transport. The AMOC is responsible for the relative warmth of the Northern Hemisphere [2].

\section{BUT HOW WILL THE OCEAN CHANGE?}

The ocean absorbs most of the sun's energy that hits Earth. Did you know that it also absorbs more than $90 \%$ of the $\mathrm{CO}_{2}$ and excess heat that humans add into the atmosphere? But can the ocean keep absorbing heat and carbon forever? Probably not. Although the ocean changes all the time, it is currently changing much faster than scientists expected (Figure 3).

Every time we add something to the ocean that was not there before, like heat or carbon, we are causing the ocean to change. So, between climate changes and human impacts, what does the future hold for the ocean? 
Figure 3

(A) The global mean sea surface

temperature and (B) global mean sea level are projected to continue increasing into the future. If we work to reduce our $\mathrm{CO}_{2}$ emissions, the changes will be lower (blue). But if we do nothing to reduce $\mathrm{CO}_{2}$ (red), the ocean could get much warmer, and the sea level will rise substantially (Image adapted from [3]).

\section{THERMAL}

\section{EXPANSION}

When a substance is heated, molecules begin to vibrate and move more, increasing the distance between themselves. This increases volume and decreases density.

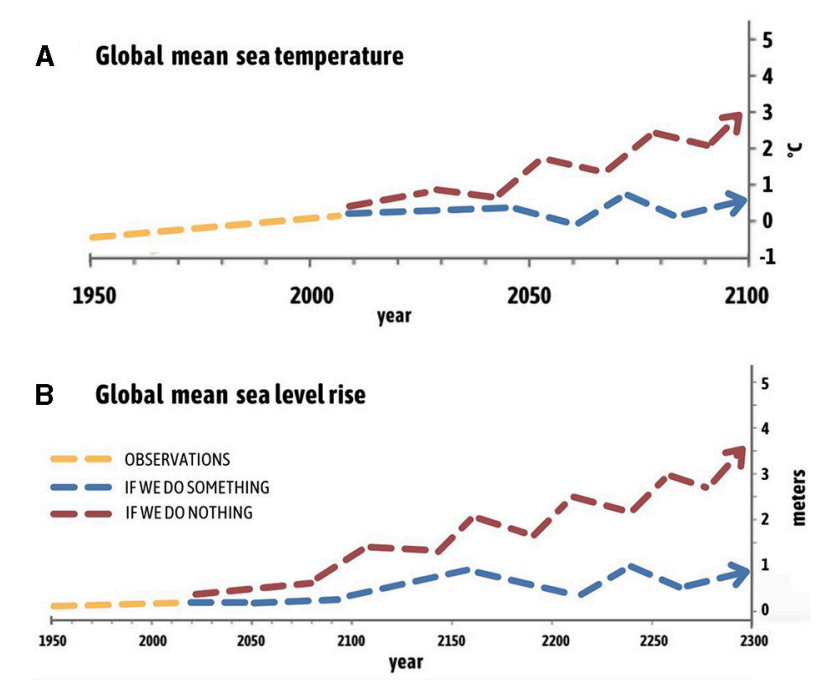

Figure 3

The mean ocean temperature is increasing. A warmer ocean will lead to a much more stratified ocean, meaning that there will be more still layers of water with less mixing. And it will be harder for water masses like we have today to be created because they need some mixing of the water to form. Changes in the formation of water masses will impact heat transport and, therefore, the Earth's climate. But some places will experience surface warming more than others. The Arctic, for example, will be more affected than other regions [4]. The problem is that the Arctic Ocean is one of the most critical water mass formation areas. If water masses do not form as readily in the Arctic, the ocean currents will probably get weaker. Researchers have already shown that the AMOC is becoming weaker, and they suggest that it is due to climate change [5].

A warming ocean can also lead to the disappearance of some coastal cities and islands. This would happen because of thermal expansion. As the temperature rises, liquid water expands and occupies a larger volume, causing the sea level to rise. The sea level will also rise as liquid water shifts from land to the ocean, due to increased discharge from rivers or melting of glaciers. Melting of ice sheets as the temperature rises can also add volume to the ocean and contribute to local sea-level rise. Read more about it in Why Should We Worry About Sea Level Change? [6]. In the last few years, sea-level rise has already been observed, and it should be carefully studied, since it can impact many people around the world, especially coastal populations.

\section{HOW CAN WE HELP?}

Climate change studies teach us how and why the ocean will change if nothing is done to stop the process. If the global ocean temperatures continue to rise, there will be many harmful effects on 
ocean organisms and humans. The ocean is one of the main regulators of rain and oxygen production. It provides us with food and helps us to move around the Earth. We all depend on the ocean! So, we need to improve and spread our knowledge about the ocean and the danger it faces. To help do so, the United Nations created the Decade of Ocean Science for Sustainable Development, between 2021 and 2030. This initiative will help us to teach people what they need to do, individually and collectively, to better manage ocean resources. If we do not start to change our habits and improve our relationship with nature, climate change will intensify and the effects of ocean temperature rise will worsen.

But we hold the power to change! We can change our personal habits, such as being mindful about our use of water and energy and reducing the single-use of plastics, also playing a key role as citizens. Kids have a crucial role in raising awareness and shaping the future. By talking about climate change with our families and friends, we can draw people's attention to this subject. We can discuss how to support policies that protect the ocean and fight climate change. We can also demand that our governments and industries act responsibly and use natural resources wisely. The sooner we take action, the higher our chances of achieving a better and brighter future for the world's ocean-and for all the animals and humans that depend on it.

\section{REFERENCES}

1. Glessmer, M. S. 2019. When water swims in water, will it float, or will it sink? Or: what drives currents in the ocean? Front Young Minds.

7:85. doi: 10.3389/frym.2019.00085

2. Buckley, M. W., and Marshall, J. 2016. Observations, inferences, and mechanisms of the atlantic meridional overturning circulation: a review. Rev Geophys. 54:5-63. doi: 10.1002/2015RG000493

3. IPCC. 2019. "Summary for policymakers," in IPCC Special Report on the Ocean and Cryosphere in a Changing Climate, eds H. O. Pörtner., D. C. Roberts., V. Masson-Delmotte., P. Zhai., M. Tignor., E. Poloczanska., et al. (IPCC).

4. Xie, S. 2020. Ocean warming pattern effect on global and regional climate change. AGU Adv. 1:e2019AV000130. doi: 10.1029/2019AV000130

5. Hu, S., and Federov, A. 2019. Indian ocean warming can strengthen the Atlantic meridional overturning circulation. Nat. Clim. Change 9:747-51. doi: 10.1038/s41558-019-0566-x

6. Siegert, M. 2017. Why should we worry about sea level change? Front. Young Minds. 5:41. doi: 10.3389/frym.2017.00041

SUBMITTED: 26 April 2021; ACCEPTED: 21 October 2021; PUBLISHED ONLINE: 16 November 2021.

EDITOR: Chris Jones, Met Office Hadley Centre (MOHC), United Kingdom 


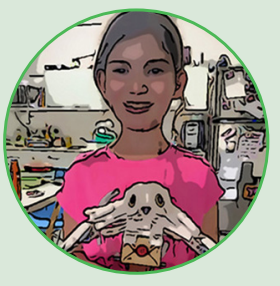

\section{YOUNG REVIEWER}

\section{AVIV, AGE: 9}

A huge Harry Potter fan! I love reading books! I spend many hours reading on my Kindle, especially Harry Potter-I have read the entire series 20 times! I also love jamming on my electric piano, jump-roping, and skipping when I am happy. I like eating salads and home cooked meals, but I also have a big sweet tooth-chocolate is yummy! As a vegetarian, I love nature-learning about it, protecting it, and enjoying it!

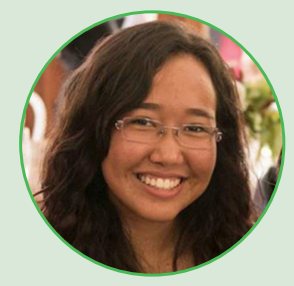

\section{AUTHORS}

\section{DENISE TYEMI FUKAI}

I am an oceanographer and I really like physics! Now, I am now trying to learn more about how the ocean is represented by climate models and how it will behave with climate change. I am currently finishing a Master's degree in meteorology at the Federal University of Rio de Janeiro (UFRJ). I work with a very interesting class of models that are meant to reproduce the main processes on Earth (Earth System Models). *denise.fukai@gmail.com

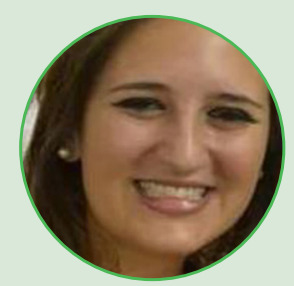

\section{ANNA BEATRIZ JONES OAQUIM}

I am an oceanographer with a Master's degree in environmental geosciences. Particularly, I am interested in understanding how the climate has changed over time, and how it can impact the future. I currently work with climate reconstructions in Antarctica and high mountain regions where we found ice and snow. For this, I use microscopic organisms such as diatoms as indicators of environmental and climatic changes, integrated with geochemistry and radiological analysis. 


\section{MAURO CIRANO}

As a physical oceanographer, I have devoted the last 3 decades to understanding the circulation in coastal and oceanic regions, both based on the analysis of oceanographic data and through numerical modeling of circulation. I am an Associate Professor at UFRJ and the coordinator of two operational oceanography programs in Brazil. At UFRJ, I teach and supervise graduate and undergraduate students. 